\title{
Mothers of Adolescents with Intellectual Disabilities: The "Meaning" of Severity Level
}

\author{
Osnat Rubin"1,2, Michal Schreiber-Divon ${ }^{3,4}$ \\ ${ }^{1}$ Department of Education, Talpiot College of Education, Holon, Israel \\ ${ }^{2}$ Department of Counseling and Human Development, University of Haifa, Haifa, Israel \\ ${ }^{3}$ Hativat Shalom, Petach Tikva, Israel \\ ${ }^{4}$ Department of Education, Talpiot College of Education, Holon, Israel \\ Email: osnatr@edu.haifa.ac.il
}

Received 21 February 2014; revised 18 March 2014; accepted 16 April 2014

Copyright (C) 2014 by authors and Scientific Research Publishing Inc.

This work is licensed under the Creative Commons Attribution International License (CC BY).

http://creativecommons.org/licenses/by/4.0/

c) (i) Open Access

\section{Abstract}

In recent years, Positive Psychology has been shedding new light on the field of research examining the parenting of a child with disabilities. This study aims to provide a bridge between the "traditional" approach which focuses on the parents' difficulties and pathologies, and the breakingthrough PP (Positive Psychology) approach which recognizes the points of strength and the positive ways of coping. The present study compared the sense of burden and the sense of personal growth among 106 mothers of adolescents with intellectual disabilities of varying severity. No differences were found between the two groups concerning the sense of burden, but among mothers of adolescents with severe intellectual disabilities, the sense of growth was higher. No differences were found in terms of the mother's age, income level, the number of children in the family, and the age of the child. The theme of "Meaning" offers possible explanations for these findings.

\section{Keywords}

Intellectual-Disabilities, Positive-Psychology, Personal-Growth

\section{Introduction}

The positive psychology research aims at understanding the positive, adaptive, fulfilling aspects of human behavior, focusing on strengths and quality of life, rather than on illness. Following this approach, many studies were conducted in recent years, showing that people have succeeded considerably in coping with conditions of crises 
such as accidents, disasters, illnesses, and that many of them even reported an increase in personal and social resources, new coping abilities and personal growth (Ott, Sanders, \& Kelber, 2007; Spielma \& Taubmab Ben Ari, 2009). Different research fields have adopted the positive psychology approach. One of these emerging fields of study is the research of parenting a child with disabilities.

Traditionally, researchers have mainly addressed the negative implications of parenting a child with disabilities. In recent years, it is possible to see a shift in the literature towards examining parental coping in a new way. The shift is from the perception of parental coping as an inevitable condition of crisis, stress and pathology, to recognizing possibly positive ways of coping. Findings of studies conducted in recent years show that despite the pain and difficulty involved in raising a child with disabilities, many parents succeed in coping positively with their lives (Maul \& Singer, 2009).

The present study aims to provide a bridge between the "traditional" approach which focuses on the parents' difficulties and pathologies, and the breaking-through PP (Positive Psychology) approach which recognizes the points of strength and the positive ways of coping. The focus of this study is the sense of burden and the sense of growth of mothers of children with intellectual disabilities, as it relates to the severity of their children's retardation.

\section{Theoretical Background}

\subsection{Positive Psychology and Personal Growth}

"Growth" is defined as a process of creating meaning following crisis and existential distress. The experience involved in crisis situations or events undermines a person's basic concepts of himself and of the world, and his usual methods of coping suddenly become inefficient and unsuitable for the new situation which has evolved. Growth, in this context, may be expressed in various manners, including, among others, renewed appreciation of life, an intensified sense of powers and strength, improvement in interpersonal relationships, change in priorities, spiritual evolvement and finding meaning and purpose in life (Znoj, 1999). These positive outcomes have been found related to (Schaefer \& Moos, 1992): crisis features (e.g., its severity, intensity and scope), personal properties (e.g., age, socioeconomic status), personality characteristics (e.g., temperament, self-confidence, earlier coping experiences), and surrounding properties (e.g., various support systems which connect with the person and affect him).

Tedeschi and Calhoun (Tedeschi \& Calhoun, 1995) offer another reference to the term "growth out of crisis". Their model emphasizes growth as a result of a traumatic event ("Posttraumatic Growth"). An exposure to a traumatic event (an event which is a threat to life or to important goals in life) might stimulate negative emotions and also physical and mental distress. But, it could also lead to personal growth, developing an adaptive ability, psychological skills and awareness. Tedeschi and colleagues (Tedeschi, Park, \& Calhoun, 1998) outlined the stressful event's nature, the person's characteristics, and the social surroundings as factors that might affect the posttraumatic growth process. In their model, Tedeschi and Calhoun (Tedeschi \& Calhoun, 1995) classified growth in four major areas: 1) Change in self-perception and an increase of the personal resources such as intensified self-confidence ('I'm more vulnerable than I thought, but I have more power and strength than I have ever imagined"); 2) Change in interpersonal relations. Following the need to talk about the event the person may behave with greater emotional openness towards others. Moreover, he may might feel more vulnerable and thus express more willingness to obtain support; 3) Change in the philosophy of life. People who experienced a traumatic event reported that trivial and obvious things became meaningful to them and gained their renewed appreciation. They have also reported about changes in life priorities, gaining renewed control over life, and also setting clear goals and targets. Naturally, the rate of occurrence of these positive changes and the goals and priorities of the new life "mosaic", vary from one person to another. What is common to all of them is a reinforced sense of purpose and meaning in life, and greater satisfaction and clarity concerning essential existential questions. In a later analysis, Calhoun and Tedeschi have added areas where growth could occur (Calhoun \& Tedeschi, 2006); 4) Increase in the level of empathy, compassion and love towards others—strengthening of the sense of compassion when faced with the anguish of others. A part of the positive development of a person's social relations originates from the new outlook he has adopted concerning others, the increasing empathy towards people, the efforts aimed at improving relationships. And, posttraumatic growth has to do with perceiving new opportunities and options-openness to new possibilities which includes broadening of the areas of interest, outlining a new way of life, increasing the number of opportunities and the willingness to change whatever requires 
changing.

\subsection{Parenting a Child with Developmental Intellectual Disability}

Developmental Intellectual Disability means actual limitations in general functioning. It is characterized by intellectual functioning significantly lower than the average, which exists along with related limitations, in two or more areas of the following functional adaptation skills: communication, self-care, household management, social skills, community orientation, self-guidance, health and safety, academic skills, utilizing leisure time, and occupational competence (Luckasson et al., 1992). The complexity of the definition of disability is expressed in its amended version: "Mental retardation is a disability characterized by significant limitations in intellectual functioning and adapting behavior as expressed in the adaptive, perceptive, social and practical skills" (AAMR, 2002: p. 8). The definition includes three mandatory components which must exist in the individual in order for him to be defined as having an intellectual disability: 1) Considerable limitation of intellectual functioning; 2) Limitation of adapting behavior, in all its aspects, related to the intellectual disability; and 3) The intellectual disability occurs before the age of 18 . According to the amended definition, classification of people with mental retardation is conducted according to an assessment of the level of support which the person requires rather than according to IQ levels, and this indicates the substantial role of the environment in the development and functioning of the person with intellectual disability.

Raising a child with intellectual disability considerably affects the family's daily life and the life course of the child's parents. This is not merely a single crisis or stressful event that requires a one-time mobilization of the family, but rather a complicated process which continues throughout a lifetime, and has its vicissitudes (Poehlmann, Clements, Abbeduto, \& Farsad, 2005). Families are required to cope with ongoing challenges and crises which affect various aspects of daily life: economic, personal, couple relationship, familial and social (Davis \& Gavidia-Pyane, 2009). The constant care requirements continue even after the child becomes an adult.

Literature about parenting a child with developmental intellectual disability describes the parents' experience as a heavy burden, especially among mothers (see: Mackey \& Goddard, 2006). The sense of burden is a result of both the Sisyphean daily care (concrete difficulties), and their concerns and worries such as the fear of the future (emotional burden). The mothers' manner of coping with raising a child with intellectual disability may be related to a wide variety of characteristics that have become the focus of studies in this field. Two of them will be addressed here below: The nature of the disability (type, severity) and the age of the child.

Studies that examined the effect of severity of disability on parental coping, showed ambivalent findings. For example, Orr and his colleagues (Orr, Cameron, Dobson, \& Day, 1993) have found that the severity of the disability is associated with the maternal stress level, while Hastings and his colleagues reported of no significant correlation between the severity of symptoms and the maternal stress (Hastings et al., 2005). With regard to the type of disability, within the literature on parenting a developmental disabled child, there seem to be a great mass of studies focusing on parents to children with autism, and a deficit of research examining the parental experience of having a child with intellectual disabilities, considering the vulnerability of this population (Hu et al., 2010).

As to the age of the child, one set of studies focuses on childhood ages as the central study population, in order to examine the parental coping upon learning about the child's disability. The second, smaller group of studies, reviews parental coping during a different phase in life, the phase of the "storm period" that accompanies the transition from childhood to adulthood: adolescence. Literature identifies this period as possessing challenges that are more complicated for the parents, particularly among parents of children with special needs. Studies show that mothers of adolescents with special needs have experienced less control over the parental role and increased concerns about the adolescent (see: Smith, Seltzer, Tager-Flusberg, \& Carter, 2008). Parents of adolescents with intellectual disabilities reported higher levels of stress and need for parental support than parents of normal adolescents (Hastings \& Beck, 2004). Moreover, reports of increased vulnerability among adolescents with special needs (for example, greater risk of depression, see; Kiddle \& Dagnan, 2011) imply for increased difficulties of parental coping with the adolescent with the disability.

In light of the above mentioned, the present study aimed to focus on the puberty age group, and examine the parenting experience of mothers of children with intellectual disabilities, in a PP approach. We sought to examine the mothers' sense of burden on the one hand and their sense of growth on the other hand, and examine whether there are differences in the mothers' experience with relation to the severity of their children's retardation. Every 
event is meaningful to a person. A stressful event entails an immediate meaning to the person, but it is also subject to ongoing changes. A part of the recovery process includes providing a meaning, either automatically or intentionally (Park, 2010). In the present study, we seek to examine the "meaning" of the severity of disability in the maternal coping, in the sense defined by Taylor (1983: p. 1161) "what does my life mean now?": the sense of difficulty (the burden) and the sense of growth. The Study Hypotheses were: 1) The sense of growth of mothers of adolescents with mild retardation will be higher in comparison with the sense of growth of mothers of adolescents with severe retardation; and 2) The sense of burden of mothers of adolescents with severe retardation will be higher in comparison with the sense of burden of mothers of adolescents with mild retardation.

\section{Method}

\subsection{Participants}

The participants in the study were 106 mothers of students of schools for the intellectually disabled. 54 of them were mothers of students who attend a school for the severely retarded and with complex disabilities (hereinafter, "sever retardation"), and 52 of them were mothers of children who attend a school for children with multiproblem mild retardation (hereinafter, "mild retardation"). The average age of the mothers was 43.3 years (SD = 6.7), $57.5 \%$ of them reported an average income level. The average age of the child with intellectual disability was 14.9 years $(\mathrm{SD}=3.13)$. The average number of children in the family was $3.04(\mathrm{SD}=1.42)$. The demographic background of the participants is detailed on Table 1.

\subsection{The Study Process}

The study was initiated by the school, which is an experimental school, and with the approval of the Experimentation and Entrepreneurship Division in the Ministry of Education. The questionnaires were delivered to the mothers in sealed envelopes. The return rate was 59\%.

\subsection{Research Tools}

In addition to a demographic questionnaire, containing information about the age of the mother, level of income, number of children and age of the child, the research tools included:

Caregiver Strain Index developed by Robinson (Robinson, 1983), including 13 5-point Likert scale items, with Cronbach's alpha of $\alpha=.86$. Example items are: "a special child in the family causes physical strain"; " $a$ special child in the family means an economic strain"; "I'm feeling completely overwhelmed". Cronbach's alpha in the present study was $\alpha=.709$.

Personal Growth out of Crisis Questionnaire-The Stress-Related Growth Scale (SRGS), a questionnaire developed by Park, Cohen \& Murch, 1996. Its abbreviated version includes 26 3-point Likert scale items (Cronbach's alpha consistency of $\alpha=.95)$. Example items are: "I have learned to respect other people's feelings and beliefs", "I have been thinking about my life and the way in which I wish to live it", "a previous relationship with another person became more meaningful”, Cronbach's alpha in the present study was $\alpha=.929$.

\section{Findings}

\subsection{Sense of Burden}

The first study hypothesis was that differences in the sense of burden will be found between mothers of adolescents

Table 1. Demographic background of the participants.

\begin{tabular}{ccccc}
\hline & \multicolumn{2}{c}{ Mild Retardation N $=52$} & \multicolumn{2}{c}{ Sever Retardation N $=54$} \\
\cline { 2 - 5 } & M & SD & M & SD \\
\hline Age of the Mother & 46.4 & 5.57 & 40.4 & 6.73 \\
Number of Children in the Family & 2.90 & 1.33 & 3.18 & 1.50 \\
Age of the Child & 16.5 & 2.93 & 13.31 & 2.44 \\
\hline
\end{tabular}


with mild retardation and mothers of adolescents with severe retardation, where the sense of burden of mothers of adolescents with severe retardation will be higher in comparison with the sense of burden of mothers of adolescents with mild retardation.

To examine the hypothesis, $\mathrm{t}$ test was performed on independent samples. The differences are shown in Table 2.

No significant differences in the sense of burden were found between mothers of adolescents with mild retardation and mothers of adolescents with severe retardation.

\subsection{Sense of Growth}

The findings of the study indicate a difference in the sense of growth between mothers of adolescents with severe retardation and mothers of adolescents with mild retardation. It was found that the sense of growth in mothers of adolescents with severe retardation was higher in comparison with the sense of growth in mothers of adolescents with mild retardation. This was contrary to the study hypothesis.

The differences are shown in Table 3.

\subsection{The Sense of Burden and the Sense of Growth in Relation to Demographic Variables}

In addition to differences in the mothers' sense of heavy burden and feeling of growth by the severity of disability, differences in the sense of burden and sense of growth were examined in relation to demographic variables: age of the mother, level of income, number of children in the family, and the age of the child. Pearson correlation tests to examine differences in relation to the mother's age, the child's age and the number of children in the family, and One-Way-Anova tests to examine differences in relation to income level, indicated that there were no significant differences.

\section{Discussion}

In the last decade, the field of Positive Psychology has rapidly established itself through a large and growing body of research. Among the highlighted themes of PP (such as happiness, meaningfulness, and spirituality), Hart and Sasso (2011) mark the engagement in resilience and coping, as a significant theme of the "second generation” of the positive psychology discipline ("PP 2.0.” as Wong, 2011, suggested naming it). This theme focuses on individuals who are situated in ecological environments of difficulty and limitation, and seeks to characterize the quality of life of people with disabilities (physical, mental or intellectual).

In the study field of parenting a child with developmental disabilities, there was a prominent shift from studies focused on difficulties, to the study of the positive aspects of growth in this situation (Manor-Binyamini, 2012). However, within this field, we found relatively few studies which examined the parental experience of parents having a child with intellectual disabilities. This population is considered to be a population with high vulnerability and risk of comorbidity, and their caregivers tend to experience a high prevalence of depression,

Table 2. Means and standard deviations of the sense of burden among mothers of adolescents with mild retardation and severe retardation.

\begin{tabular}{ccccc}
\hline & $\mathrm{N}$ & $\mathrm{M}$ & $\mathrm{SD}$ & $\mathrm{t}_{(102)}$ \\
\hline Mothers of Adolescents with Mild Retardation & 50 & 3.07 & 1.25 & $\mathrm{NS}$ \\
Mothers of Adolescents with Severe Retardation & 54 & 2.98 & 1.06 & \\
\hline
\end{tabular}

Table 3. Means and standard deviations of the sense of growth among mothers of adolescents with mild retardation and severe retardation.

\begin{tabular}{cccc}
\hline & $\mathrm{N}$ & $\mathrm{M}$ & $\mathrm{SD}$ \\
\hline Mothers of Adolescents with Mild Retardation & 52 & 1.93 & 0.45 \\
Mothers of Adolescents with Severe Retardation & 54 & 2.1 & 0.33 \\
\hline
\end{tabular}

Note: ${ }^{*} p<0.05$. 
burden, and psychological distress (Hu et al., 2010). Therefore it seems especially important to examine aspects of PP in this population. Additionally, researches in this field focus, in most cases, on childhood ages, and do not examine the parental experience during a period which is considered tumultuous and challenging to parents-the wide range of adolescence (youth). Parents of adolescents are situated in a process of ongoing care for a disabled child and therefore it is important to examine the sense of burden and sense of growth in light of this ongoing experience of caregiving (Manor-Binyamini, 2012).

The present study examined the sense of burden and the sense of growth among mothers of adolescents with intellectual disabilities. We sought to learn whether there are differences in these aspects between mothers of adolescents with mild mental retardation and mothers of adolescents with severe mental retardation. The hypothesis was that among mothers of children with severe mental retardation, the sense of burden will be higher and the sense of growth will be lower, in comparison with the mothers of children with mild retardation. However, contrary to the study hypotheses, no differences in the sense of burden were found between the two groups. However, it was found that the sense of growth among the mothers of adolescents with severe mental retardation was higher in comparison with the sense of growth among the mothers of adolescents with mild retardation. Prima facie, this finding is inconsistent with some previous studies that describe the complexity and the experience of difficulty in parenting a disabled child, indicating a growing sense of difficulty, stress hopelessness in correlation with higher severity of the disability (Abbeduto et al., 2004; Baker, Blacher, Crnic, \& Edelbrook, 2002).

What are, then, the possible explanations for these findings? Considering the literature in the field of positive psychology on the one hand and the research on parenting children with disabilities on the other hand, may shed light on the findings.

We seek to use the theme of "meaning" to offer a possible explanation for the findings. Raising a child with mental retardation is considered a stressful situation. Park (2010) lists a number of ways to deal with events which are potentially stressful, by the attribution of meaning. According to Park, a sense of growth involves changing the meaning of the event to a more positive one, regardless of whether the perceived changes are veridical (Park, 2008). Likewise, in our study, differences among mothers were found in the sense of growth with the increase in severity of the disability, even if no actual changes in the situation were perceived (in the sense of burden) between the groups.

Why was the feeling of growth among the mothers of adolescents with a more severe intellectual disability higher than among the mothers in the second group? This finding can be explained in three different ways (at least):

First, perhaps mothers of adolescents with milder disability are having difficulty to utilize a process of producing a meaning, which results in growth. Perhaps the more severe the adolescent's condition is, the higher becomes the parent's awareness of his child's difficulties, he accepts the situation, and his dream of his child functioning almost normally, fades. In contrast, among mothers of children with lower severity of the disability, the proximity of the situation to "normal" continues to attract their attention. In this situation, it is possible that mothers of adolescents with mild intellectual disabilities are engaged in ongoing attempts of producing meaning with "no results" (Park, 2010). This process was described by Park (2010) as a kind of rumination, which is an indication of an increased sense of stress. Emotion-focused coping (including a focus on the emotions raised by the stressful event, such as the sense of burden), as opposed to problem-focused coping (including an approach of growth out of the event) is attributed in literature to a state of helplessness.

Smith and his colleagues (2008) argue that the problem-focused coping skills are acquired as the child grows up. The present research adds to this field of knowledge, and shows that in the same age group, the severity of the problem is what takes the parents on to the PP journey. It appears that one of the implications of the study is the suggestion to support specifically the mothers of children with mild (!) retardation, who are relatively less utilizing or less successful in utilizing growth processes.

The second possible explanation is that the more a person is facing a growing difficulty, the more he tries to find strengths. Viktor Frankl $(1969,1987)$ coined the approach of searching for meaning as a person's main source of motivation. One basis of his theory is that suffering also has meaning, and a search for meaning takes place especially when a person cannot remove the cause of his distress. Despair means to suffer without meaning. According to Frankel, recognizing the meaning in unavoidable suffering is one of the sources of coping with a situation of difficulty. Perhaps mothers of children with severe mental retardation are actively coping using growth, precisely because they cannot remove the cause of their distress-the harsh disability of their child. 
However, mild retardation might be perceived as suffering that could be avoided, because of its proximity to the "normal".

The third explanation relates to the comments of Calhoun and Tedeschi (2006) who point out a connection between growth and an increase in the level of empathy, compassion and love towards others, strengthening the sense of compassion where faced with the anguish of others, a new outlook that the individual adapts for himself regarding others, and increasing sensibility towards people. It may be that maternal care for a child with a higher rate of disability triggers these aspects to a greater extent.

The contribution of the study is the understanding that the severity of the disability is not necessarily linked with the sense of burden, but rather it is mediated by aspects of positive psychology such as a sense of growth. It should be noted that the methodological complexity of this field of study suggests the need for further studies. A list of factors in the parent's characteristics (such as income level, education level, religiosity etc.) are known to affect the perception of parental stress among parents of children with disabilities (Manor-Binyamini, 2012). In our study, no significant differences were found in the sense of growth or the sense of burden in terms of income level, age of the mother, age of the child, and the number of children in the family, but it is clear to us that the picture is intricate.

This study sets an additional layer in the field of study that attempts to examine the parental coping with raising a child with disabilities and particularly among parents of adolescents with mental disability, and its relation to the severity of the disability. This study responds to the call for more attention to the positive experiences of the parents, due to their potential and practical value for improving support systems (Hatton \& Emerson, 2003). The matter at hand is not merely one of adaptive coping but rather of coping that can lead to benefit, positive adapting and positive effects on the familial system (Flaherty \& Glidden, 2000). Our findings point to the positive aspects of coping with the stressful experience of raising a child with disabilities, where the mothers have a critical impact on the whole family’s coping with the disability (Kimura \& Yamazaki, 2013).

\section{Acknowledgements}

This study was funded by the Department of Experimental Schools, Ministry of Education, on Hativat Shalom, Petach Tikva, Israel, with the support of Tami Shternlicht.

\section{References}

Abbeduto, L., Seltzer, M. M., Shattuck, P., Krauss, M. W.,Orsmond, G., \& Murphy, M. M. (2004). Psychological Wellbeing and Coping in Mothers of Youths with Autism, Down Syndrome, or Fragile X Syndrome. American Journal on Mental Retardation, 109, 237-254. http://dx.doi.org/10.1352/0895-8017(2004)109<237:PWACIM>2.0.CO;2

AAMR (American Association of Mental Retardation) (2002). Mental Retardation: Definition, Classification and Systems of Supports (10th ed.). Washington, DC: AAMR.

Baker, B. L., Blacher, J., Crnic, K., \& Edelbrook, C. (2002). Behavior Problems and Parenting Stress in Families of Three Year Old Children with and without Developmental Delays. American Journal of Mental Retardation, 107, 433-444. http://dx.doi.org/10.1352/0895-8017(2002)107<0433:BPAPSI>2.0.CO;2

Calhoun, L. G., \& Tedeschi, R. G. (2006). The Foundations of Posttraumatic Growth: An Expanded Framework. In L. G. Calhoun, \& R. G. Tedeschi (Eds.), Handbook of Posttraumatic Growth: Research and Practice (pp. 3-23). Mahwah, NJ: Lawrence.

Davis, K., \& Gavidia-Payne, S. (2009). The Impact of Child, Family, and Professional Support Characteristics on the Quality of Life in Families of Young Children with Disabilities. Journal of Intellectual \& Developmental Disability, 34, $153-162$. http://dx.doi.org/10.1080/13668250902874608

Flaherty, E. M., \& Glidden, L. M. (2000). Positive Adjustment in Parents Rearing Children with down Syndrome. Early Education and Development, 11, 407-422. http://dx.doi.org/10.1207/s15566935eed1104_3

Frankl, V. E. (1969). The Will to Meaning: Foundations and Applications of Logotherapy. New York and Cleveland: The World Publishing Company.

Frankl, V. E. (1978). The Unheard Cry for Meaning. Psychotherapy and Humanism. New York: Simon and Schuster.

Hart, K., \& Sasso, T. (2011). Mapping the Contours of Contemporary Positive Psychology. Canadian Psychology, 52, 82-92. http://dx.doi.org/10.1037/a0023118

Hastings R. P., \& Beck A. (2004) Practitioner Review: Stress Intervention for Parents of Children with Intellectual Disabilities. Journal of Child Psychology and Psychiatry, 45, 1338-1349. http://dx.doi.org/10.1111/j.1469-7610.2004.00357.x

Hastings, R. P., Kovshoff, H., Ward, N. J., Degli Espinosa, F., Brown,T., \& Remington, B. (2005). Systems Analysis of 
Stress and Positive Perceptions in Mothers and Fathers of Pre-School Children with Autism. Journal of Autism and Developmental Disorders, 35, 635-644. http://dx.doi.org/10.1007/s10803-005-0007-8

Hatton, C., \& Emerson, E. (2003). Families with a Person with Intellectual Disabilities: Stress and Impact. Current Opinion in Psychiatry, 16, 497-501. http://dx.doi.org/10.1097/00001504-200309000-00002

Hu, J., Lin, J. D, Yen, C. F., Loh, C. H., Hsu, S. W., Lin, L. P., \& Wu, S. R. (2010). Effectiveness of a Stress-Relief Initiative for Primary Caregivers of Adolescents with Intellectual Disability. Journal of Intellectual \& Developmental Disability, 35, 29-35.

Kiddle, H., \& Dagnan, D. (2011) Vulnerability to Depression in Adolescents with Intellectual Disabilities. Advances in Mental Health and Intellectual Disabilities, 5, 1-8. http://dx.doi.org/10.5042/amhid.2011.0010

Kimura, M., \& Yamazaki, Y. (2013). The Lived Experience of Mothers of Multiple Children with Intellectual Disabilities. Qualitative Health Research, 23, 1307-1319. http://dx.doi.org/10.1177/1049732313504828

Luckasson, R., Coulter, D. L., Polloway, E. A., Reiss, S., Schalock, R. L., Snell, M. E. (1992). Mental Retardation: Definition, Classification, and Systems of Supports (9th ed.). Washington, DC: American Association on Mental Retardation.

Mackey, S., \& Goddard, L. D. (2006). The Experience of Health and Wellness in Mothers of Young Children with Intellectual Disabilities. Journal of Intellectual Disabilities, 10, 305-315.

Manor-Binyamini, I. (2012). Parental Coping with Developmental Disorders in Adolescents within the Ultraorthodox Jewish Community in Israel. Journal of Autism and Developmental Disorders, 42, 815-826. http://dx.doi.org/10.1007/s10803-011-1313-y

Maul, C. A., \& Singer, G. H. (2009). “Just Good Different Things”: Specific Accommodations Families Make to Positively Adapt to Their Children with Developmental Disabilities. Topics in Early Childhood Special Education, 29, 155-170. http://dx.doi.org/10.1177/0271121408328516

Orr, R. R., Cameron, S. J., Dobson, L. A., \& Day, D. M. (1993). Age-Related Changes in Stress Experienced by Families with a Child Who Has Developmental Delays. Mental Retardation, 31, 171-176.

Ott, C. H., Sanders, S., \& Kelber, S. T. (2007). Grief and Personal Growth Experience of Spouses and Adult Child Caregivers of Individuals with Alzheimer Disease and Related Dementias. The Gerontologist, 47, 798-809. http://dx.doi.org/10.1093/geront/47.6.798

Park, C. L., Cohen, L. H., \& Murch, R. L. (1996). Assessment and Prediction of Stress-Related Growth. Journal of Personality, 64, 71-104. http://dx.doi.org/10.1111/j.1467-6494.1996.tb00815.x

Park, C. L. (2008). Overview of Theoretical Perspectives. In C. L. Park, S. Lechner, M. H. Antoni, \& A. Stanton (Eds.), Positive Life Change in the Context of Medical Illness: Can the Experience of Serious Illness Lead to Transformation? (pp. 11-30). Washington, DC: American Psychological Association.

Park, C. L. (2010). Making Sense of the Meaning Literature: An Integrative Review of Meaning Making and Its Effects on Adjustment to Stressful Life Events. Psychological Bulletin, 136, 257-301. http://dx.doi.org/10.1037/a0018301

Poehlmann, J., Clements, M., Abbeduto, L., \& Farsad, V. (2005). Family Experiences Associated with a Child’s Diagnosis of Fragile X or Down Syndrome: Evidence for Disruption and Resilience. Mental Retardation, 43, 255-267. http://dx.doi.org/10.1352/0047-6765(2005)43[255:FEAWAC]2.0.CO;2

Robinson, B. C. (1983). Validation of a Caregiver Strain Index. Journal of Gerontology, 38, 344-348. http://dx.doi.org/10.1093/geronj/38.3.344

Schaefer, J. A., \& Moos, G. H. (1992). Life Crises and Personal Growth. In B. N. Carpenter (Ed.), Personal Coping: Theory, Research and Application (pp. 149-170). Westport, CT: Praeger

Smith, L. E., Seltzer, M. M., Tager-Flusberg, H., Greenberg, J. S., \& Carter, A. S. (2008). A Comparative Analysis of WellBeing and Coping among Mothers of Toddlers and Mothers of Adolescents with ASD. Journal of Autism Developmental Disorders, 38, 876-889. http://dx.doi.org/10.1007/s10803-007-0461-6

Spielma, V., \& Taubman Ben Ari, O. (2009). Parental Self-Efficacy and Stress-Related Growth in the Transition to Parenthood: A Comparison between Parents of Pre- and Full-Term Babies. Health \& Social Work, 34, 201-212. http://dx.doi.org/10.1093/hsw/34.3.201

Taylor, S. E. (1983). Adjustment to Threatening Events: A Theory of Cognitive Adaptation. American Psychologist, 38, 1161-1173. http://dx.doi.org/10.1037/0003-066X.38.11.1161

Tedeschi, R. G., \& Calhoun, L. G. (1995). Trauma and Transformation: Growing in the Aftermath of Suffering. Thousand Oaks, CA: Sage. http://dx.doi.org/10.4135/9781483326931

Tedeschi, R. G., Park, C. L., \& Calhoun, L. G. (1998). Posttraumatic Growth: Future Directions. In R. G. Tedeschi, C. L. Park, \& L. G. Calhoun (Eds.), Posttraumatic Growth: Positive Changes in the Aftermath of Crisis (pp. 215-238). Mahwah, NJ: Erlbaum.

Wong, P. T. P. (2011). Positive Psychology 2.0: Towards a Balanced Interactive Model of the Good Life. Canadian Psychology, 52, 69-81. http://dx.doi.org/10.1037/a0022511 